\title{
New Slovak geomagnetic repeat station network
}

\author{
Fridrich Valach, Magdalena Vaczyova, and Peter Dolinsky \\ Geomagnetic Observatory Hurbanovo, GPI SAS, Slovakia
}

(Received April 22, 2005; Revised August 31, 2005; Accepted September 12, 2005; Online published June 2, 2006)

\begin{abstract}
Six geomagnetic repeat stations were established over the territory of Slovakia. The locations of the observation points were chosen in a way to provide long time series of geomagnetic measurements at the same places (or nearly the same ones). Thus the series start in the middle of the 19 th century. In this paper, the long time series of three geomagnetic elements $D, H$ and $I$ are reviewed. Results of the last geomagnetic measurements at the six observation points (reduced to the 2004.5 epoch) are presented and linear models of the distribution of geomagnetic elements and of their secular variations are shown.
\end{abstract}

Key words: Magnetic field, secular variations, magnetic survey.

\section{Introduction}

According to the agreement made during the Workshop on European Magnetic Repeat Station Surveys at Niemegk, Germany, 2003, six geomagnetic repeat stations were established over the territory of Slovakia (Valach et al., 2004). For the choice of the suitable observation places, the following criteria were adopted:

(a) Repeat stations have to be distributed over the country regularly (the required density is at least 1 station per 15000 square kilometres - the distance between neighbouring stations is about 125 kilometres).

(b) Strong local geomagnetic anomalies have to be avoided.

(c) The observation points used in previous ground surveys and having long series of measured geomagnetic elements are employed.

(d) The stations have to be free of artificial disturbances in geomagnetic field.

Geomagnetic surveys over the Slovak territory started in the middle of the 19th century, when first such a survey was performed by Karl Kreil (Barta, 1954). It was made in 1848 at eight observation points. Declination $(D)$, inclination $(I)$ and horizontal component $(H)$ were determined. Two more surveys were carried out in the 19th century, by Guido Schenzl in 1867-1869 and by Ignátz Kurländer in 1892-1894 (Schenzl, 1869; Barta, 1954). In the 20th century, six ground surveys were accomplished. They were reduced to the epochs: 1932.0 - only declination (Čechura, 1934), 1936.5-only declination (Běhounek, 1939), 1952.5 (Ochaba, 1959), 1967.5 (Krajčovič and Németh, 1972), 1980.5 (Podsklan, 1987) and 1995.5 (Váczyová, 1999).

\section{The New Network of Repeat Stations}

On the basis of the previous surveys mentioned above, six old observation points were chosen as new repeat stations. Their names and geographical coordinates are stored

Copyright (c) The Society of Geomagnetism and Earth, Planetary and Space Sciences (SGEPSS); The Seismological Society of Japan; The Volcanological Society of Japan; The Geodetic Society of Japan; The Japanese Society for Planetary Sciences; TERRAPUB. in Table 1. The positions of the stations are shown in the simple map (Fig. 1).

New measurements of the geomagnetic elements at the six localities were performed in 2004. At the observation points, complete series of $D$ and $I$ measurements with the DI-flux theodolite (Zeiss Theo 015B with Elsec 810) were carried out. We employed the same procedure as the standard procedure for the observatory measurements. Each DI-flux measurement was supplemented with 10 PPM measurements (EDA magnetometer) of the total magnetic field. In addition, at each observation point we performed five measurements of $H$ and two or three measurements of $D$ with QHM and QD instruments, respectively. Results from these old-fashioned equipments did not differ significantly from those obtained using standard DI-flux method. Therefore we included them to the results, too. The measurements were carried out in daytime. No special requirements, about what part of day to use, were adopted. Only limitation rised from the need to have good conditions for the determination of astronomical azimuths. We determined them from the observations of the Sun.

The data obtained were reduced to the 2004.5 epoch. For this purpose, the records of geomagnetic field from the Hurbanovo Geomagnetic Observatory were used. The reduction to the 2004.5 epoch was made under the assumption that the transient variations of the magnetic field are identical on the whole territory of Slovakia and equal to the variation at Hurbanovo. We used the following formula to obtain the reduced values based on those observed in the field:

$$
E_{s t, 2004.5}=E_{s t, t}-\left(E_{\mathrm{HRB}, t}-E_{\mathrm{HRB}, 2004.5}\right)
$$

where $E_{s t, t}$ is the value an arbitrary element of the geomagnetic field at the repeat station for time $t, E_{\mathrm{HRB}, t}$ is the value of the element of the geomagnetic field at the Hurbanovo observatory for time $t$ and $E_{\mathrm{HRB}, 2004.5}$ is the same for the 2004.5 epoch.

The time series of geomagnetic elements $D, H$ and $I$ at the six station's positions are stored in Table 2. Some older data presented in the table were reduced to the nowadays 
Table 1. Geographical coordinates of the repeat stations.

\begin{tabular}{llccc}
\hline No & Repeat Station & $\begin{array}{c}\text { Geograph. } \\
\text { Latitude }\left[{ }^{\circ}\right]\end{array}$ & $\begin{array}{c}\text { Geograph. } \\
\text { Longitude }\left[{ }^{\circ}\right]\end{array}$ & $\begin{array}{c}\text { Altitude } \\
{[\mathrm{m}]}\end{array}$ \\
\hline 1 & Hurbanovo & 47.88 & 18.20 & 112 \\
2 & Očkov & 48.65 & 17.755 & 160 \\
3 & Rajec & 49.09 & 18.65 & 487 \\
4 & Rimavská Sobota & 48.375 & 20.02 & 239 \\
5 & Spišské Podhradie & 49.00 & 20.73 & 520 \\
6 & Úbrež & 48.79 & 22.125 & 140 \\
\hline
\end{tabular}

Table 2. Geomagnetic elements $D, H$ and $I$ at six stations over the territory of Slovakia since the 19 th century.

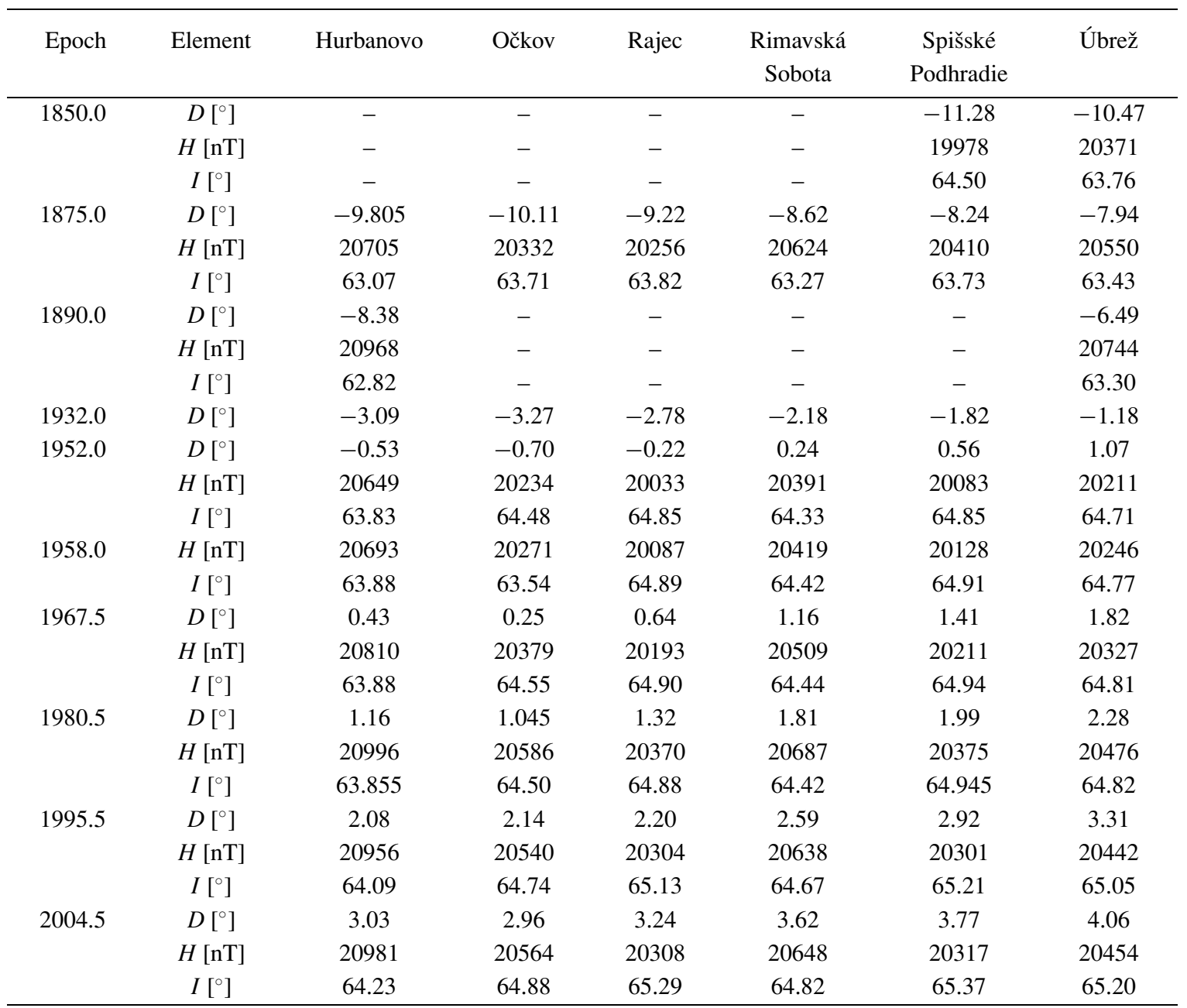

positions of the observation points. These values of geomagnetic elements were determined by linear interpolation. This procedure used three nearest points for which the geomagnetic field value are known in the given epoch (Valach et al., 2004). We have not any information about the accuracy of the old measurements from the 19th century but we assume that the old data could be less reliable than the new ones (because of less precise equipments, etc.). For that reason we used three geomagnetic elements, $D, H$, and $I$ in this paper, which were measured directly in the first surveys. Thus the errors caused by a transformation to other geomagnetic elements are not added to the old data.

\section{Distribution of the Geomagnetic Elements and Secular Variation}

In order to visualize the distribution of geomagnetic elements $D, H$ and $I$ over the territory, linear models for the 2004.5 epoch, based on the six observation points, were constructed. The linear models are described by equations

$$
\begin{aligned}
D= & (3.055 \pm 0.032)+(0.053 \pm 0.039) \cdot\left(\varphi-\varphi_{\mathrm{HRB}}\right) \\
+ & (0.256 \pm 0.011) \cdot\left(\lambda-\lambda_{\mathrm{HRB}}\right), \\
H & =(20970 \pm 15)-(545 \pm 19) \cdot\left(\varphi-\varphi_{\mathrm{HRB}}\right) \\
& -(11.4 \pm 5.1) \cdot\left(\lambda-\lambda_{\mathrm{HRB}}\right),
\end{aligned}
$$




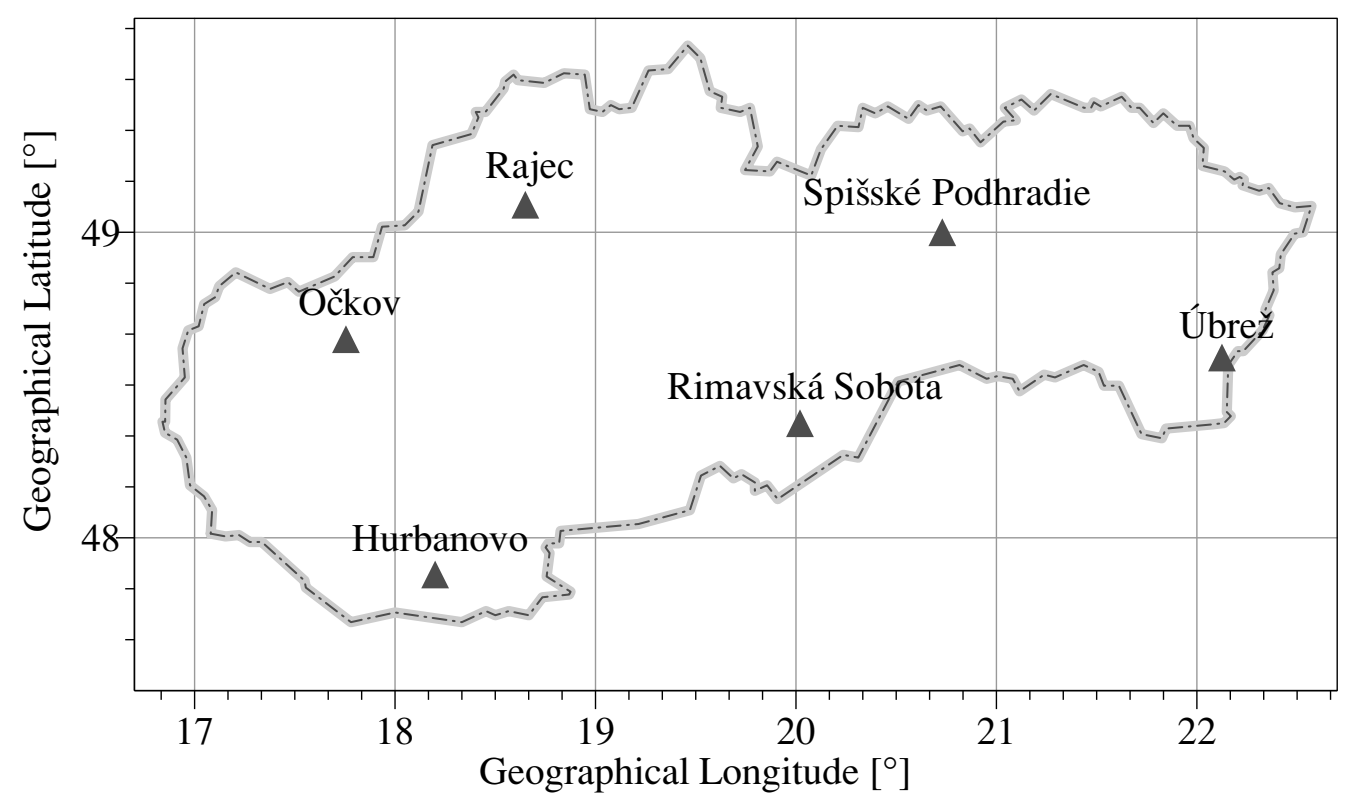

Fig. 1. The distribution of six repeat stations in Slovakia.

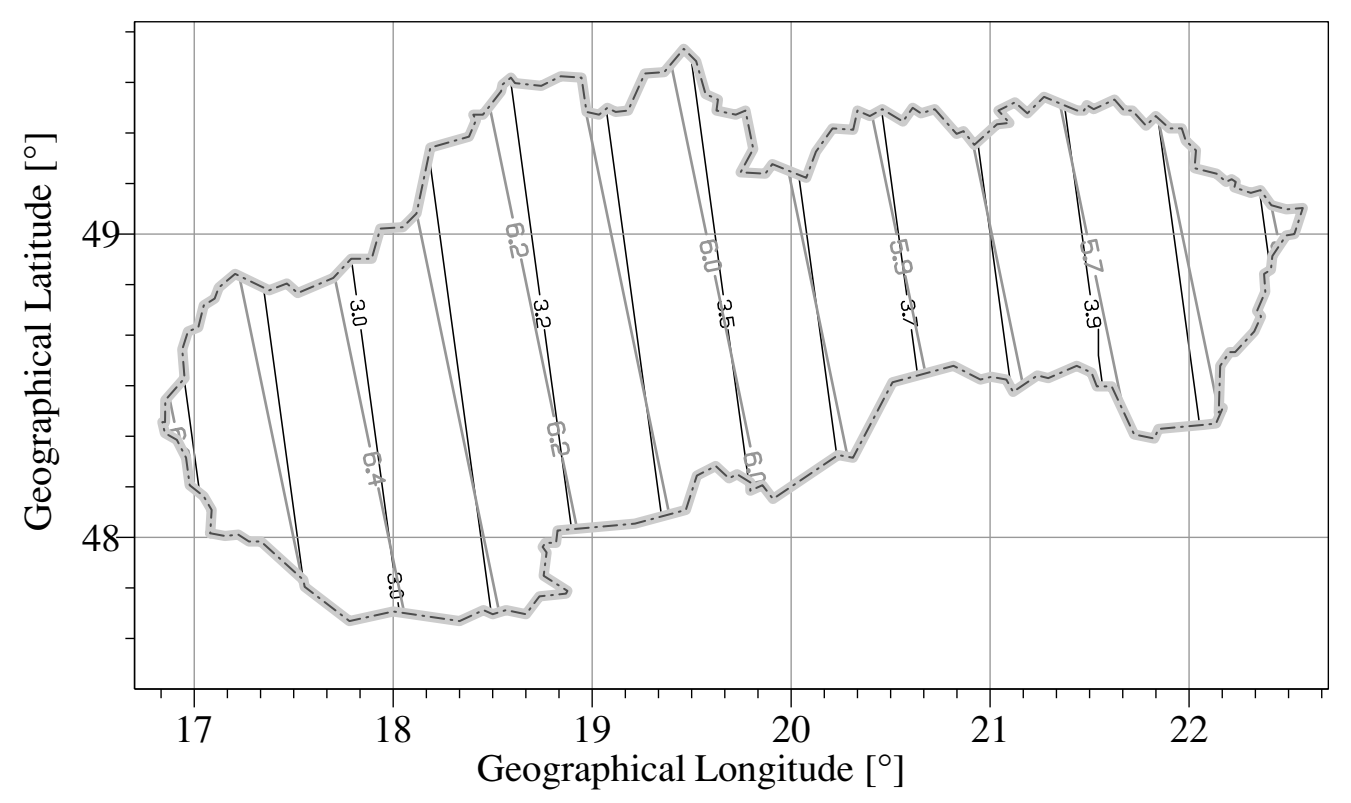

Fig. 2(a). Linear models for the distributions of declination for the 2004.5 epoch (solid lines) and for its secular variation (grey lines) between 1995.5 and 2004.5. Declination is expressed in arc degrees and its secular variation in arc minutes per year.

$$
\begin{aligned}
I & =(64.248 \pm 0.028)+(0.849 \pm 0.034) \cdot\left(\varphi-\varphi_{\mathrm{HRB}}\right) \\
& +(0.0555 \pm 0.0091) \cdot\left(\lambda-\lambda_{\mathrm{HRB}}\right) .
\end{aligned}
$$

Declination $(D)$, inclination $(I)$, longitude $(\lambda)$ and latitude $(\varphi)$ are expressed in arc degrees, horizontal component $(H)$ in nanoteslas. The coordinates for Hurbanovo $\left(\varphi_{\mathrm{HRB}}\right.$, $\left.\lambda_{\mathrm{HRB}}\right)$, are quoted in Table 1 .

Secular variations of geomagnetic elements can be visualized by linear models, too. The following equations represent such models

$$
\begin{aligned}
\dot{D} & =(6.36 \pm 0.53)-(0.06 \pm 0.66) \cdot\left(\varphi-\varphi_{\mathrm{HRB}}\right) \\
& -(0.19 \pm 0.17) \cdot\left(\lambda-\lambda_{\mathrm{HRB}}\right)
\end{aligned}
$$

$$
\begin{aligned}
\dot{H} & =(2.66 \pm 0.50)-(1.05 \pm 0.62) \cdot\left(\varphi-\varphi_{\mathrm{HRB}}\right) \\
& -(0.12 \pm 0.16) \cdot\left(\lambda-\lambda_{\mathrm{HRB}}\right)
\end{aligned}
$$

$$
\begin{aligned}
\dot{I} & =(54.0 \pm 1.5)+(4.7 \pm 1.9) \cdot\left(\varphi-\varphi_{\mathrm{HRB}}\right) \\
& +(0.90 \pm 0.50) \cdot\left(\lambda-\lambda_{\mathrm{HRB}}\right) .
\end{aligned}
$$

Secular variation for declination is expressed in arc minutes per year, for inclination in arc seconds per year and for horizontal component the values are in nanoteslas per year. Isolines for these models are shown in Figs. 2(a)-(c). 


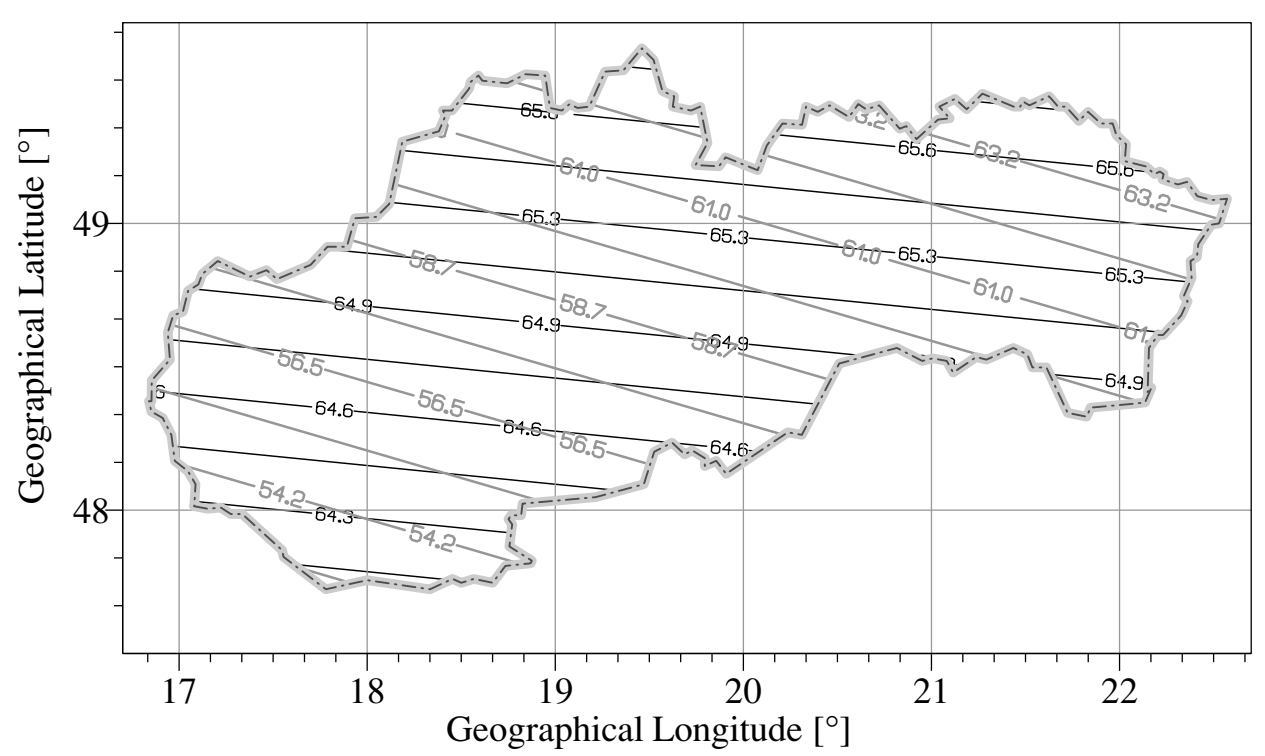

Fig. 2(b). Linear models for the distributions of horizontal component for the 2004.5 epoch (solid lines) and for its secular variation (grey lines) between 1995.5 and 2004.5. Horizontal component is expressed in nanoteslas and its secular variation in nanoteslas per year.

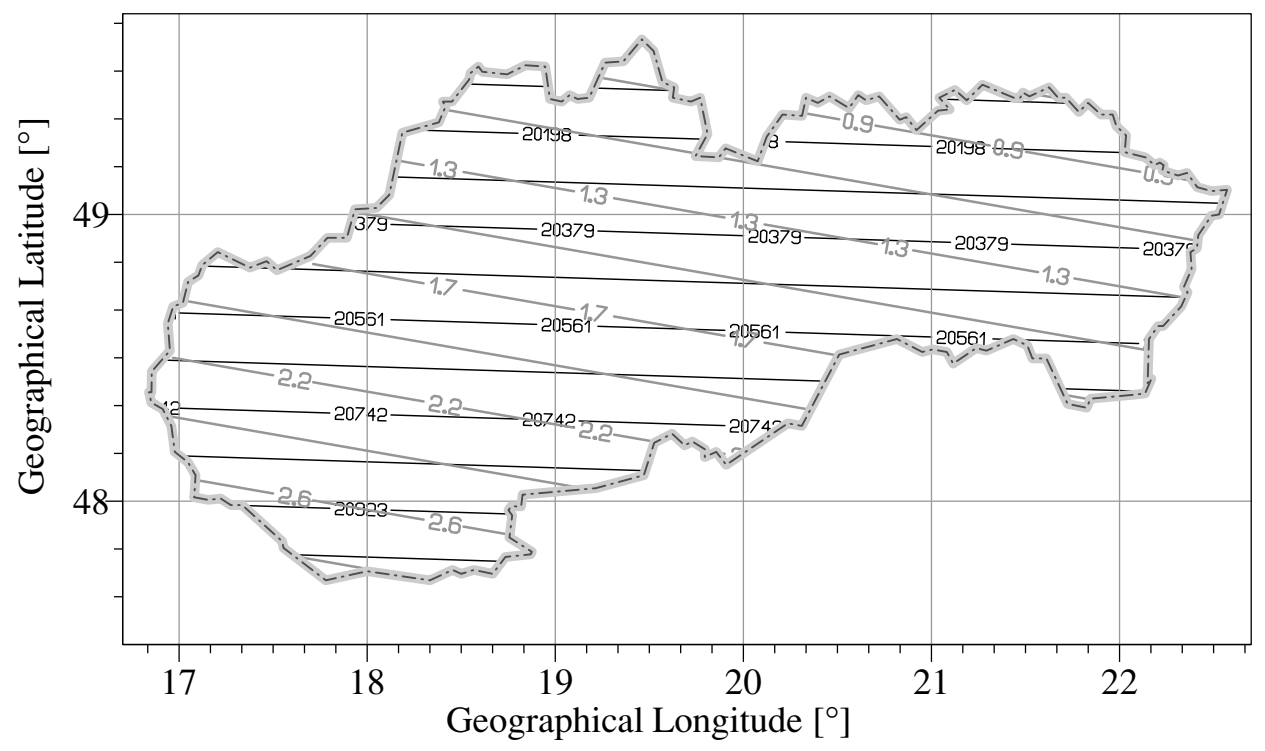

Fig. 2(c). Linear models for the distributions of inclination for the 2004.5 epoch (solid lines) and for its secular variation (grey lines) between 1995.5 and 2004.5. Inclination is expressed in arc degrees and its secular variation in arc seconds per year.

\section{Conclusion}

The new Slovak repeat station network, established for the purposes of common European geomagnetic repeat station survey, was reoccupied in 2004. The measurements of the geomagnetic field at the six observation points were reduced to the middle of 2004 (i.e. to the 2004.5 epoch). Time series of geomagnetic elements at these points were shown. Linear models of the distribution of geomagnetic elements $D, H, I$ and of their secular variations were constructed.

We compared the observed values with IGRF-10 (http://www.ngdc.noaa.gov/IAGA/vmod/igrf.html). Average differences for geomagnetic elements (observed minus IGRF) are:

$$
\begin{aligned}
& \overline{\Delta D}=(0.01 \pm 0.02)^{\circ}, \quad \overline{\Delta H}=(-14 \pm 6) \mathrm{nT}, \\
& \overline{\Delta I}=(-0.01 \pm 0.01)^{\circ} .
\end{aligned}
$$

For secular variations we obtained:

$$
\begin{aligned}
& \overline{\Delta \dot{D}}=(1.5 \pm 0.3)^{\prime} \cdot \mathrm{yr}^{-1}, \\
& \overline{\Delta \dot{H}}=(-4.9 \pm 0.3) \mathrm{nT} \cdot \mathrm{yr}^{-1}, \\
& \overline{\Delta \dot{I}}=(0.28 \pm 0.08)^{\prime} \cdot \mathrm{yr}^{-1}
\end{aligned}
$$

The typical feature of geomagnetic field, westward drift, can be deduced from the models od $D$ and $\dot{D}$. Because the isogones are nearly perpendicular to the west-east direction, the rate of westward movement of the isogones can be estimated, using Eqs. $2 \mathrm{a}$ and $3 \mathrm{a}$, to be $0.40^{\circ} \cdot \mathrm{yr}^{-1}$. This estimate seems to be reasonable. It exceeds the widely adopted value of $0.18^{\circ} \cdot \mathrm{yr}^{-1}$ for global westward drift. On the other hand, it is less then $0.61^{\circ} \cdot \mathrm{yr}^{-1}$ found by Barraclough and Malin (1999), whose value is based mainly on the records of European observations. 
The data from repeat station surveys are an important source for secular variation studies, for modelling of geomagnetic field (both on the local and global scales), for studies in geology, but also in practice (e.g., for navigation purposes). Within the period between two detailed magnetic ground surveys, which are usually performed not more then once a decade, the results from repeat stations enable us to improve and update the detailed geomagnetic maps of the territory. In order to meet the demands requested for the abovementioned purposes, we propose the repeat stations to be reoccupied at least every two years.

Acknowledgments. The authors are grateful to VEGA, the Slovak grant agency (grant No. 2/1118/23) for the partial support of this work.

\section{References}

Barraclough, D. R. and S. R. C. Malin, A fast-moving features of westward drift, Annali di Geofisica, 42/1, 21-26, 1999.

Barta, Gy., Changes of Geomagnetic Strength in Hungary, Akadémiai kiadó, Budapest, 1954 (in Hungarian).
Běhounek, R., Magnetic Measurements in Slovakia, in Moravian-Silesia Land and in Carpathian Ukraine, Státní ústav geofisikální, Prague, 46 pp., 1939 (in Czech).

Čechura, F., Magnetic declination in Slovakia for the 1932.0 epoch, Sborník prírodovedeckého klubu v Košiciach, sv. II, 1-30, 1934 (in Czech).

Krajčovič, S. and M. Németh, Distribution of the geomagnetic field in Slovakia for epoch 1967.5, Contr. Geophys. Inst. SAS, 3, 16-24, 1972.

Ochaba, Š., Distribution of Geomagnetic Field in Slovakia for the 1952.5 epoch, Geofisikální sborník, 92, Prague, 319-356, 1959 (in Slovak).

Podsklan, J., Distribution of the Earth magnetic field on the territory of Slovakia for the epoch 1980.5, Contr. Geophys. Inst. SAS, 17, 111-141, 1987.

Schenzl, G., Magnetic Field Measurements in Kingdom Hungary, Wien, 1869 (in German).

Váczyová, M., Distribution of the Earth's magnetic field on the territory of Slovakia for the 1995.5 epoch, Contributions to Geophysics and Geodesy, 29/4, 269-284, 1999.

Valach, F., M. Váczyová, and P. Dolinský, Geomagnetic repeat stations network over the territory of Slovakia, Contributions to Geophysics and Geodesy, 34/1, 21-42, 2004.

F. Valach (e-mail: fridrich@geomag.sk), M. Vaczyova, and P. Dolinsky 